De bolichero turco a ganadero árabe. La construcción territorial de un inmigrante libanés en el noroeste del Chubut (1907-1927)

\title{
De bolichero turco a ganadero árabe. La construcción territorial de un inmigrante libanés en el noroeste del Chubut (1907-1927)
}

\section{From Turkish bolichero to Arab rancher. The territorial construction of a Lebanese immigrant in the northwest of Chubut (1907-1927)}

\author{
Matías Rodrigo Chávez \\ Instituto Patagónico de Ciencias Sociales y Humanas, \\ Centro Científico Tecnológico, Centro Nacional Patagónico \\ Consejo Nacional de Investigaciones Científicas y Técnicas (Argentina)
}

\begin{abstract}
Resumen
Este artículo estudia la trayectoria de un inmigrante libanés durante las primeras décadas del siglo XX en el paraje El Maitén, analizando sus estrategias socio-políticas para la construcción de una territorialidad inicialmente comercial y luego también ganadera. Se centra en la descripción de sus disputas territoriales, siguiendo los expedientes producidos por diferentes agencias estatales que tuvieron intervención en los sucesivos conflictos. Este estudio de caso problematiza su ciclo de acumulación y diversificación, buscando propiciar el debate sobre los procesos de construcción territorial de los bolicheros sirio-libaneses en la Patagonia central.
\end{abstract}

\section{Palabras clave}

Patagonia; inmigración; sirio-libaneses; tierra pública; territorialidad

\begin{abstract}
This article studies the trajectory of a Lebanese immigrant during the first decades of the 20th century in El Maitén, analyzing his socio-political strategies for the construction of an initially commercial and then also cattle rancher territoriality. It focuses on the description of his territorial disputes, following the records produced by different state agencies that had intervention in the successive conflicts. This case study problematizes his cycle of accumulation and diversification, seeking to encourage debate on the processes of territorial construction of the Syrian-Lebanese bolicheros in central Patagonia.
\end{abstract}

\section{Keywords}

Patagonia; immigration; Syrian-Lebanese; public land; territoriality

Esta obra está sujeta a la Licencia Reconocimiento-NoComercial-CompartirIgual 4.0 Internacional de Creative Commons. http://creativecommons.org/licenses/by-nc-sa/4.0/ (cc) BY-NC-sa 


\section{Campos abiertos y territorios superpuestos}

La historiografía patagónica ha caracterizado el ciclo de ascenso económico experimentado por muchos inmigrantes sirio-libaneses como el tránsito exitoso de comerciantes a ganaderos propietarios, aunque la vigencia de esa fórmula explicativa no se condice con la disponibilidad de estudios de caso que la verifiquen. Por ello consideramos que reconstruir la trayectoria del inmigrante libanés Abraham Breide puede propiciar el debate sobre los procesos de movilidad y las estrategias socio-políticas de los inmigrantes sirio-libaneses. Con ese objetivo analizaremos las disputas de tierras protagonizadas por Breide, interpelando la documentación producida por la Gobernación del Territorio Nacional del Chubut y por la Dirección Nacional de Tierras y Colonias, es decir las agencias estatales con competencia para arbitrar en los conflictos.

Se trata de comprender el proceso que permitió que Breide controlase una territorialidad extensa, entendiendo por territorialidad a la estrategia de un individuo o grupo de afectar, influir o controlar personas, fenómenos y sus relaciones, a través de la delimitación y ejerciendo control sobre una geografía1. Este tipo de territorialidades podían adoptar forma de redes y podían devenir territorios, a partir de los cuales se transformaban en áreas cercadas o en disputa. Como veremos, esta evolución se ajusta en buena medida a la trayectoria de acumulación y diversificación experimentada por Breide.

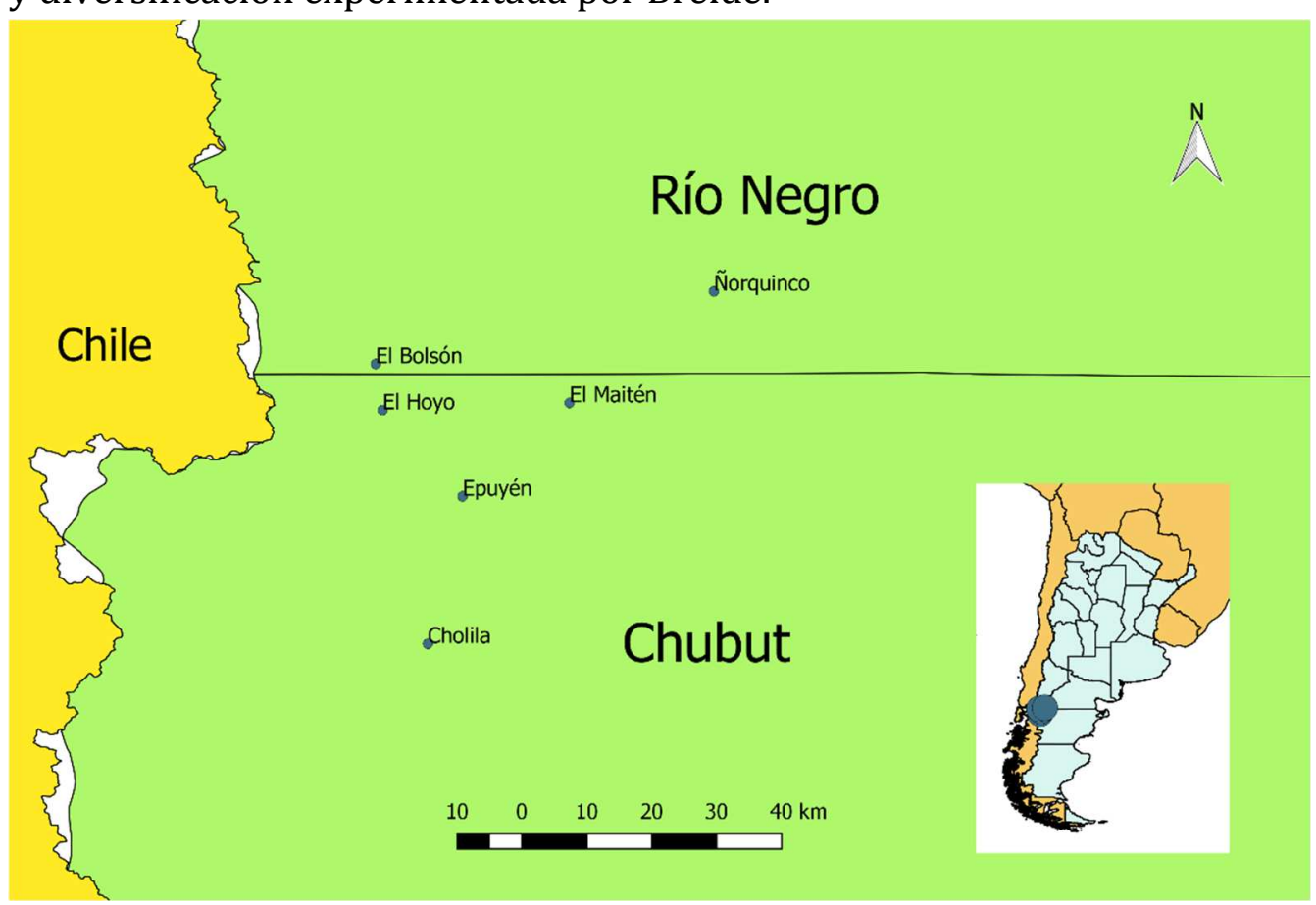

Fig. 1. Mapa del noroeste del Chubut (Fuente: elaborado por el autor).

\footnotetext{
${ }^{1}$ Alejandro Benedetti. "Territorio: concepto integrador de la geografía contemporánea", en Patricia Souto, (coordinadora), Territorio, lugar, paisaje. Prácticas y conceptos básicos en geografía. Buenos Aires, Editorial de la Facultad de Filosofía y Letras de la Universidad de Buenos Aires, 2011, p. 45.
} 


\section{De bolichero turco a ganadero árabe. La construcción territorial de un inmigrante libanés en el noroeste del Chubut (1907-1927)}

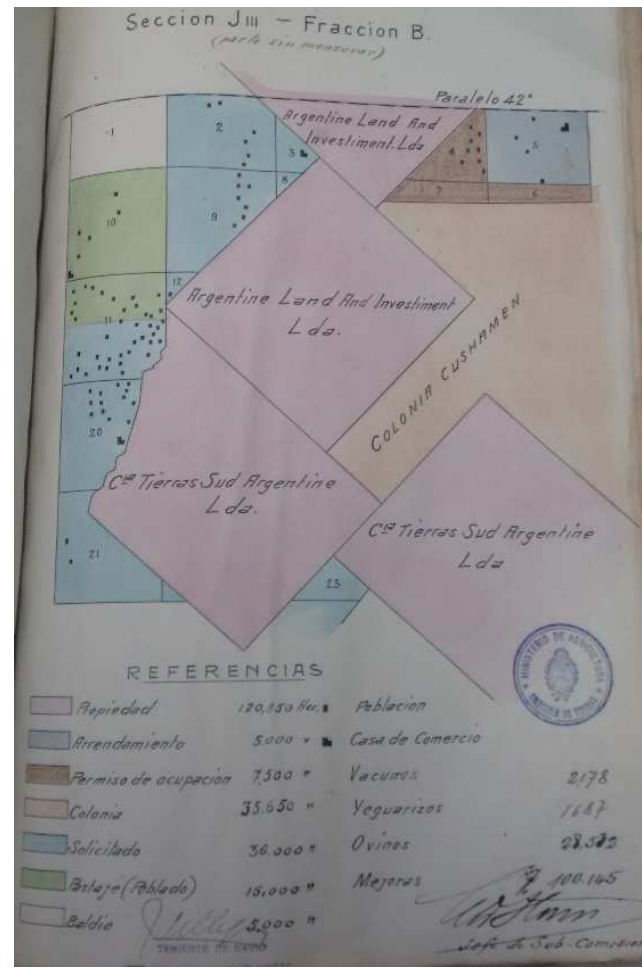

Fig. 2. Plano fracción B, sección JIII. Instituto Autárquico de Colonización y Fomento Rural, Inspecciones Generales de Tierras, sección JIII, Chubut, 1920, f. 223
Para contextualizar la discusión debemos señalar que Abraham Breide fue durante las primeras décadas del siglo XX el principal bolichero de El Maitén, un pequeño paraje del noroeste del Chubut que contaba con una población heterogénea articulada en lo fundamental a partir de la estancia homónima de la Argentine Southern Land Co. (en adelante $A S L C o.)^{2}$. Dicha compañía había acaparado las mejores tierras y era la principal empresa terrateniente de la región, empleando al grueso de los pobladores del paraje.

Es importante señalar el antecedente de que Breide había tenido una serie de conflictos con la ASLCo. por la competencia comercial que representaba su boliche para el almacén de la estancia Leleque. Los comercios de la compañía le permitían a la empresa mantener en sus arcas parte de los salarios de los empleados, favorecían la sujeción de los trabajadores en el lugar y garantizaban que a estos no se les despachasen bebidas alcohólicas ${ }^{3}$. La ASLCo.

había recurrido en distintas oportunidades a la policía del Chubut para denunciar la venta de alcohol en el boliche de Breide ${ }^{4}$, en una clara tentativa por eliminarlo como competidor 5 .

El boliche de Breide ocupaba un lugar estratégico, considerando que El Maitén estaba ubicado en una encrucijada de caminos que replicaban antiguas rastrilladas indígenas y era paso obligado para vadear el río Chubut en sentido

\footnotetext{
${ }^{2}$ La memoria local refiere que la mayoría de los pobladores del paraje se desplazaron en tres oportunidades. Del emplazamiento original que databa de fines del siglo XIX sobre las sierras de El Maitén se mudaron hacia la aldea escolar en la década de 1920, para finalmente radicarse en el emplazamiento actual a fines de la década de 1930 producto de la instalación de la estación y los talleres del ferrocarril (El Maitén, su historia...su poblamiento.... El Maitén, Municipalidad del Maitén, 2006, p. 5).

${ }^{3}$ Eduardo Míguez. Las Tierras de los ingleses en la Argentina 1870-1914. Buenos Aires, Editorial de Belgrano, 1985, pp. 280-281.

${ }^{4}$ Ramón Minieri. Ese ajeno sur. Viedma, Fondo Editorial Rionegrino, 2006, p. 197.

${ }^{5}$ Abraham Breide tuvo una serie de conflictos con las fuerzas policiales en las dos primeras décadas del siglo XX, efectuando reiteradas denuncias ante lo que consideraba persecuciones personales que atentaban contra su libertad de comercio (Ernesto Maggiori. 6 historias patagónicas. Trelew, Remitente Patagonia, 2017, pp.142-145). Como la policía emitía los certificados de antecedentes este tipo de enfrentamientos podían condicionar las posibilidades de obtener patentes comerciales o tramitar permisos de ocupación de la tierra. No obstante estos conflictos fueron habituales para los inmigrantes árabes en todo el país durante los primeros años del siglo XX, sus denuncias contra la violencia policial fueron replicadas en los principales medios de prensa (Alejandro Schamún. La colectividad siria en la República Argentina. Buenos Aires, s/d, 1910, p. 17).
} 
norte-sur. Por allí pasaba el camino real ${ }^{6}$ que conectaba a Nahuel Huapi con Esquel y la ruta que unía Cholila con Ñorquinco ${ }^{7}$. El río y distintos cursos hídricos menores ofrecían disponibilidad de agua durante todo el año, y se contaba además con la presencia de bosques que permitían usar madera como combustible y cubrir parcialmente la necesidad de insumos para la construcción. Finalmente, el relieve accidentado precordillerano permitía acceder a campos de veranada e invernada relativamente cercanos.

Los gobiernos nacionales habían mostrado un temprano interés en las potencialidades productivas de la zona, estimándose desde comienzos del siglo XX que por allí pasaría una importante línea férrea que articularía la región con el mercado mundial ${ }^{8}$. Lo cierto es que el estado argentino demoró la administración efectiva sobre la propiedad inmobiliaria en esos espacios estratégicos, pese a que el control y reparto de tierras en zonas de frontera resultó fundamental para efectivizar finalmente su soberanía9 ${ }^{9}$ Para 1920 las únicas dependencias estatales en El Maitén eran el destacamento de policía que dependía de la comisaría de Leleque -ubicada en el casco de la estancia del mismo nombre- y el edificio destinado a una escuela que habían donado los vecinos, pero que en ese momento no funcionaba.

Para conocer las condiciones en que se hallaban los pobladores antes de los conflictos territoriales que aquí nos ocupan, contamos con la descripción que ofrece la Inspección General de Tierras de 192010. La riqueza de esta fuente documental obedece a que los inspectores de tierras realizaron un relato pormenorizado sobre

\footnotetext{
${ }^{6}$ Desde la época colonial se denominaba como caminos reales a las rutas generales que conectaban las principales localidades, dichas franjas de terreno eran responsabilidad de los gobiernos nacionales.

${ }^{7}$ El carácter estratégico de la ocupación de Breide fue señalado por Machi en su caracterización de los inmigrantes sirio-libaneses del noroeste del Chubut (Gabriela Macchi. "Los sirio-libaneses y su participación en el temprano desarrollo económico del noroeste del Chubut 1900-1940". X Congreso de Historia Social y Política de la Patagonia Argentino-Chilena, Trevelin, 2013).

${ }^{8}$ Marcelino Martínez. La Patagonia Central. Descripción física y política de la Gobernación del Chubut. Buenos Aires, Lajuane y Cía. Editores, 1913, p. 108.

${ }_{9}^{9}$ Juan Pro Ruiz. "Introducción. Mensuras, catastro y construcción estatal", en Juan Carlos Garavaglia y Pierre Gautreau, (editores), Mensurar la tierra, controlar el territorio. América Latina, siglos XVIIIXIX. Rosario, Prohistoria ediciones, 2011, p. 20.

${ }^{10}$ Existen antecedentes significativos de estudios sobre la ocupación de la tierra fiscal en la región, fundamentalmente sobre los parajes de Cholila y Cushamen (Débora Finkelstein. "Mecanismos de acceso a la tierra y narraciones de identidad en la colonia pastoril aborigen de Cushamen (provincia del Chubut)". Cuadernos del Instituto Nacional de Antropología y Pensamiento Latinoamericano, № 19. Buenos Aires, 2001, pp. 231-247; Débora Finkelstein, María Marta Novella y Marcelo Gavirati. "Ocupación de la tierra pública en el noroeste del Chubut. Poblamiento y producción agropecuaria en el valle de Cholila, sección JIII, (1900-1919)". II Congreso de Historia Social y Política de la Patagonia argentino-chilena, Trevelin, 1997; Débora Finkelstein y María Marta Novella. Poblamiento del Noroeste del Chubut. Aportes para su historia. Esquel, Fundación Ameghino, 2005; Liliana Figueroa. "Las tierras destinadas a pastos comunes en Cholila: aportes para definir al sujeto poblador y pensar los cambios en el uso y tenencia de la tierra". Revista Hermeutic, № 9. Río Gallegos, 2010, pp. 1-22. Destacándose la investigación de Sourrouille, quien reconstruyó las relaciones de interacción y conflicto entre tres modelos de organización y uso de los recursos en el noroeste del Chubut: la Colonia 16 de Octubre, la reserva Nahuelpan y la Argentine Southern Land Co. (Marcos Sourrouille. Nahuelpan, Colonia 16 de octubre y Argentine Southern Land Co.: la colonización del Territorio Nacional del Chubut (1885-1937). Tesis doctoral Universidad de Buenos Aires, Buenos Aires, 2017).
} 


\section{De bolichero turco a ganadero árabe. La construcción territorial de un inmigrante libanés en el noroeste del Chubut (1907-1927)}

los ocupantes y sus condiciones materiales. Esos informes evaluaron y clasificaron a los pobladores, condicionando fuertemente sus posibilidades de acceder a la tierra a partir de atributos como la raza y la nacionalidad ${ }^{11}$.

Según consta en la inspección, Breide poblaba el lote 3 con una casa de comercio ubicada en la margen noreste del río Chubut, a la vera del camino general. El comerciante libanés fue clasificado como turco, registrándose que su residencia databa de 190712. Se determinó que el fundamento de la ocupación era mercantil, si bien contaba con algunos cultivos, un molino y con un importante número de animales, hacienda que no tenía una marca específica ya que eran el producto del cobro de deudas a sus clientes. El informe de Breide fue favorable, recomendado el otorgamiento del derecho de arrendamiento, aunque sus construcciones fueron calificadas como "primitivas".

\begin{tabular}{|c|c|c|c|c|c|c|}
\hline Poblador & Nacionalidad & Ocupación & $\begin{array}{r}\text { Valor total } \\
\text { hacienda }\end{array}$ & $\begin{array}{r}\text { Extensión } \\
\text { cultivada }\end{array}$ & $\begin{array}{r}\text { Valor total } \\
\text { útiles de } \\
\text { labranza }\end{array}$ & $\begin{array}{r}\text { Valor total } \\
\text { mejoras }\end{array}$ \\
\hline Abraham Breide & Turco & Comerciante & $\$ 4.670$ & 37 ha & $\$ 7.130$ & $\$ 7.980$ \\
\hline $\begin{array}{l}\text { Sociedad Idelfonso } \\
\text { Bellosta y sucesión } \\
\text { Domínguez }\end{array}$ & Español & Criador & $\$ 29.656$ & Sin cultivos & Sin materiales & $\$ 1.180$ \\
\hline Ismael Alvarado & Chileno & Fletero de carros & $\$ 17.460$ & 15 ha & $\$ 5.825$ & $\$ 4.120$ \\
\hline Francisco Liempe & Indígena chileno & Criador & $\$ 10.587$ & 6 ha & Sin materiales & $\$ 750$ \\
\hline Segundo Guajardo & Chileno & Criador & $\$ 12.625$ & 4 ha & $\$ 70$ & $\$ 2.230$ \\
\hline Bautista Caniu & Argentino & Criador & $\$ 3.170$ & 6 ha & Sin materiales & $\$ 615$ \\
\hline Venancio Quiroga & Argentino & Capataz de la $A S L C o$. & $\$ 1.850$ & Huerta & Sin materiales & $\$ 275$ \\
\hline Antonio Inaipil & Chileno & Sin datos & & Sin cultivos & Sin materiales & Sin datos \\
\hline Segundo Niripil & Indígena argentino & Agente de policía & $\$ 3.720$ & 14 ha & $\$ 347$ & $\$ 450$ \\
\hline José Tomás Lezcano & Sin datos & Sin datos & Sin datos & Sin cultivos & Sin materiales & Sin datos \\
\hline Juan de Dios Liempe & Sin datos & Sin datos & $\$ 1.950$ & Sin cultivos & Sin materiales & $\$ 380$ \\
\hline
\end{tabular}

Fig. 3. Cuadro pobladores de los lotes 2, 3, 8 y 9 de la fracción B, sección JIII (Fuente: Instituto Autárquico de Colonización y Fomento Rural, Inspecciones Generales de Tierras, sección JIII, Chubut, 1920).

Los ocupantes linderos a Breide eran mayoritariamente pequeños criadores cuyo mayor capital eran sus animales (como se refleja en el cuadro de la figura 3). En ese escenario, el bolichero árabe se destacaba por el valor de sus bienes aunque su diferenciación económica respecto a sus vecinos no era aún del todo marcada. En líneas generales la inspección remarcó la escasez de las inversiones, criticando reiteradamente lo que consideraba como "falta de apego al trabajo", aunque justificó

11 Brígida Baeza. Fronteras e identidades en Patagonia central (1885-2007). Rosario, Prohistoria ediciones, 2009, p. 51 y Graciela Blanco. "Los ocupantes de tierras en la Norpatagonia. Los Inspectores nacionales, el colono ideal y el poblador real al comenzar el siglo XX". Historia Regional, Vol. XXIX. Villa Constitución, 2016, p. 53.

12 Pese al citado registro de 1907, no se puede determinar con certeza la antigüedad de Breide en El Maitén, considerando que en sus distintas declaraciones policiales durante la década de 1920 sostuvo que se había radicado en la región en 1908. 


\section{Matías Rodrigo Chávez}

parcialmente la ausencia de mejoras como un resultado lógico ante la falta de previsibilidad legal ${ }^{13}$.

Pese a la recurrente crítica a la composición social de la región, en la mayoría de los casos se recomendó el otorgamiento de los permisos de arrendamiento solicitados. La inspección sugirió la subdivisión de los campos para precisar los límites, recomendando que se garantizara que los interesados arrendarían campos altos y bajos -es decir de veranada e invernada-, estimando que los campos podían soportar 1.600 animales de ganado menor o 320 animales de ganado mayor por legua en promedio. También se registraron solicitudes de personas no radicadas en el paraje como Huntly Macdonall -administrador de la ASLCo. en la sección El Maitén-, quien solicitó cuatro leguas. La propia ASLCo. solicitó 20.000 hectáreas, petición que la inspección recomendaba declinar considerando que dicha empresa ya ocupaba 200.000 hectáreas de tierra fiscal, otra evidencia irrefutable de las desigualdades territoriales.

La mayoría de los campos estaban sin alambrar, lo que redundaba en que las haciendas se mezclaran en los campos abiertos. Como veremos más adelante, los ocupantes pagaban de manera discontinuada derechos de pastaje sobre extensiones de campo indeterminadas que se prolongaban hasta sus respectivos vecinos linderos. Esa superposición territorial generaba que distintos pobladores solicitaran el arrendamiento de las mismas tierras, como sospechaba el inspector era el caso de Bautista Liempe y Segundo Guajardo ${ }^{14}$.

La inspección de tierras expuso las condiciones que propiciarían conflictos territoriales en el corto plazo, las ocupaciones sin avales estatales determinaban la inestabilidad de los pobladores. Como veremos en las siguientes páginas, entraría así en crisis lo que Ricardo Fisch denominó como el "derecho en la Patagonia"15, un ordenamiento territorial precario basado en el respeto mutuo e impreciso entre los ocupantes. Este sería un panorama muy similar al detectado por Juan Manuel Palacio para el sur bonaerense durante la misma época: el funcionamiento de una cultura legal local sui generis que mantenía la convivencia en relativa armonía entre vecinos a partir de arreglos rudimentarios, dentro de un contexto caracterizado por un régimen legal laxo y una débil presencia del estado ${ }^{16}$. La llegada de un inmigrante italiano que intentó disputar la territorialidad de Breide, pondría en tensión ese delicado equilibrio.

\section{El fin de la "perfecta armonía"}

\footnotetext{
13 Siguiendo a Ricardo Fisch podemos suponer que el bajo valor de las mejoras efectuadas en tierras fiscales podía obedecer a la falta de garantías que tenían los pobladores de seguir ocupando las tierras, inhibiéndolos de realizar inversiones que no sabían si podían conservar (Ricardo Fisch. Cuestiones patagónicas. Tierras fiscales y otros problemas. Buenos Aires, Kidd, 1932, pp. 15-16).

${ }^{14}$ Instituto Autárquico de Colonización y Fomento Rural, Inspecciones Generales de Tierras, sección JIII, Chubut, 1920, f. 248.

15 Ricardo Fisch. Cuestiones patagónicas...,Op. Cit., p. 12.

16 Juan Manuel Palacio. La paz del trigo. Cultura legal y sociedad local en el desarrollo agropecuario pampeano, 1890-1945. Buenos Aires, Edhasa, 2004, pp. 15-17.
} 


\section{De bolichero turco a ganadero árabe. La construcción territorial de un inmigrante libanés en el noroeste del Chubut (1907-1927)}

Nos interesa realizar una descripción detallada de la disputa entre Abraham Breide y Mario Pezzali, un litigio que se extendió por más de cuatro años, demostrando que existían mecanismos legales complejos que les permitieron defenderse frente a los agentes estatales. Veremos que los afectados intentaron probar la antigüedad y legitimidad de sus ocupaciones, buscaron el aval de vecinos y personajes prestigiosos de la región, recurrieron a mediadores y reclamaron ante autoridades de sus respectivos países de origen moviendo todos los engranajes legales que estuvieron a su alcance. El litigio tuvo distintos virajes, aunque siempre estuvo condicionado por las distancias y los lentos tiempos administrativos del estado.

La causa se inició en diciembre de 192117, a partir de que el oficial Pedro Grimi (encargado de la comisaría de Cholila) informó a la gobernación que Pezzali levantaba construcciones para los edificios del destacamento de policía y la oficina de correos en El Maitén. La actuación de Grimi respondía a la denuncia efectuada por Breide, en compañía de Ismael Alvarado. El comerciante árabe manifestó que él había ofrecido con anterioridad la donación de los edificios públicos ante el Ministerio del Interior. La gobernación confirmó el antecedente de la donación de Breide y ordenó detener las construcciones mientras se realizaban las averiguaciones.

En enero de 1922 se le tomó declaración a Breide, quien ratificó las denuncias efectuadas ante la Gobernación y la Dirección General de Tierras y Colonias. Denunciaba que el poblador italiano Mario Pezzali se había introducido en el campo que él ocupaba en noviembre de 1920, iniciando construcciones ilegitimas, lo que había ocasionado el extravío de algunos animales de su propiedad. El comerciante libanés aducía que él había sido el primer poblador del lugar y que los que estuvieron después fueron desalojados. El argumento de "la primera ocupación" fue una constante en la causa, pese a que la ley de tierras № 4167 de 1903 negaba derechos especiales basados en la antigüedad de las poblaciones. Su principal argumento era que según el decreto del 4 de junio de 1917 no se podían introducir mejoras en campos fiscales, debiendo mantenerse la situación de quienes pagaban derecho de pastaje, es decir mantener las ocupaciones de los vecinos linderos que reconocía como ocupantes legítimos: Ismael Alvarado y la sociedad de Idelfonso Bellosta con sucesión Domínguez.

Tanto Alvarado como Bellosta avalaron la denuncia de Breide, sosteniendo que pese a que Pezzali decía contribuir con la construcción de oficinas públicas, había reconocido entre sus allegados que proyectaba una "fonda". El argumento central de Alvarado era que no se justificaba la donación de Pezzali ya que este no era "capitalista" y no tenía la suficiente antigüedad en el pueblo como para justificar

17 Archivo Histórico de la Provincia de Chubut, Fondo Gobernación del Chubut, expediente № 3535, $13 / 12 / 1921$. 


\section{Matías Rodrigo Chávez}

una donación, manifestando su convicción de que el único objetivo de Pezzali era congraciarse con las agencias estatales ${ }^{18}$.

El 10 de enero la gobernación intimó a Pezzali para que deshiciera sus construcciones. El 23 de enero Grimi procedió a la destrucción de las mejoras, al parecer sin que mediase una decisión definitiva del gobernador. Inmediatamente Pezzali denunció lo que consideraba arbitrariedades policiales y pidió protección ante el consulado italiano. Era habitual que los inmigrantes recurriesen a los representantes diplomáticos de su país de origen, el propio Breide lo había hecho por lo menos en dos oportunidades ${ }^{19}$.

El 30 de mayo de 1922 Breide realizó una nueva denuncia alegando que Pezzali había reiniciado sus construcciones. El 15 de julio el inspector de policía Arístides Saccone les tomó nuevas declaraciones a las partes. Breide reconoció que no poseía título de propiedad sino solicitudes de concesión ante la Dirección de Tierras que databan de 1916. Sostuvo que ignoraba la extensión total de su ocupación, calculando una legua en sentido norte y sur atravesando en río Chubut. Declaró además que había levantado cuatro mil metros de alambrados en 1911, época en que no se requería permisos especiales. Sin embargo admitió que en 1920 había continuado parte de sus alambrados sin permiso de la gobernación. En cuanto a los materiales de construcción, había utilizado madera de tierras fiscales previo permiso de la Dirección General de Agricultura y Defensa Agrícola, y la madera restante se la había comprado a la $A S L C o .$. Esto último matiza el carácter conflictivo de la relación con la compañía inglesa. Resulta llamativo que ninguna de las actuaciones policiales requirió que compareciera algún representante de la ASLCo., considerando su "vecindad" al conflicto.

En su declaración Alvarado no pudo asegurar si la ocupación de Pezzali se encontraba dentro de las tierras que él había solicitado. A su entender el verdadero problema era que afectaba a las tierras en que pastaban sus animales, los de Breide y los de Bellosta, pese a que reconoció que Pezzali no había introducido animales. En el mismo sentido declaró Bellosta, aduciendo que pese a que Pezzali había ocupado solamente una hectárea, sus construcciones afectaron la "perfecta armonía" de los colindantes ${ }^{20}$.

\footnotetext{
${ }^{18}$ Archivo Histórico de la Provincia de Chubut, Fondo Gobernación del Chubut, expediente № 3535, 13/12/1921, f. 15.

${ }^{19}$ En enero de 1914 Breide había denunciado persecución policial ante el consulado Otomano en Buenos Aires (Archivo Histórico de la Provincia de Chubut, Fondo Gobernación del Chubut, expediente № 2465, 20/11/1914) y en agosto de 1917 había pedido protección al consulado alemán -en ese momento gerente del consulado general de Turquía- por amenazas (Archivo Histórico de la Provincia de Chubut, Fondo Gobernación del Chubut, expediente № 2347, 04/08/1917).

${ }^{20}$ Archivo Histórico de la Provincia de Chubut, Fondo Gobernación del Chubut, expediente № 3535, 13/12/1921, fs. 66-71.
} 


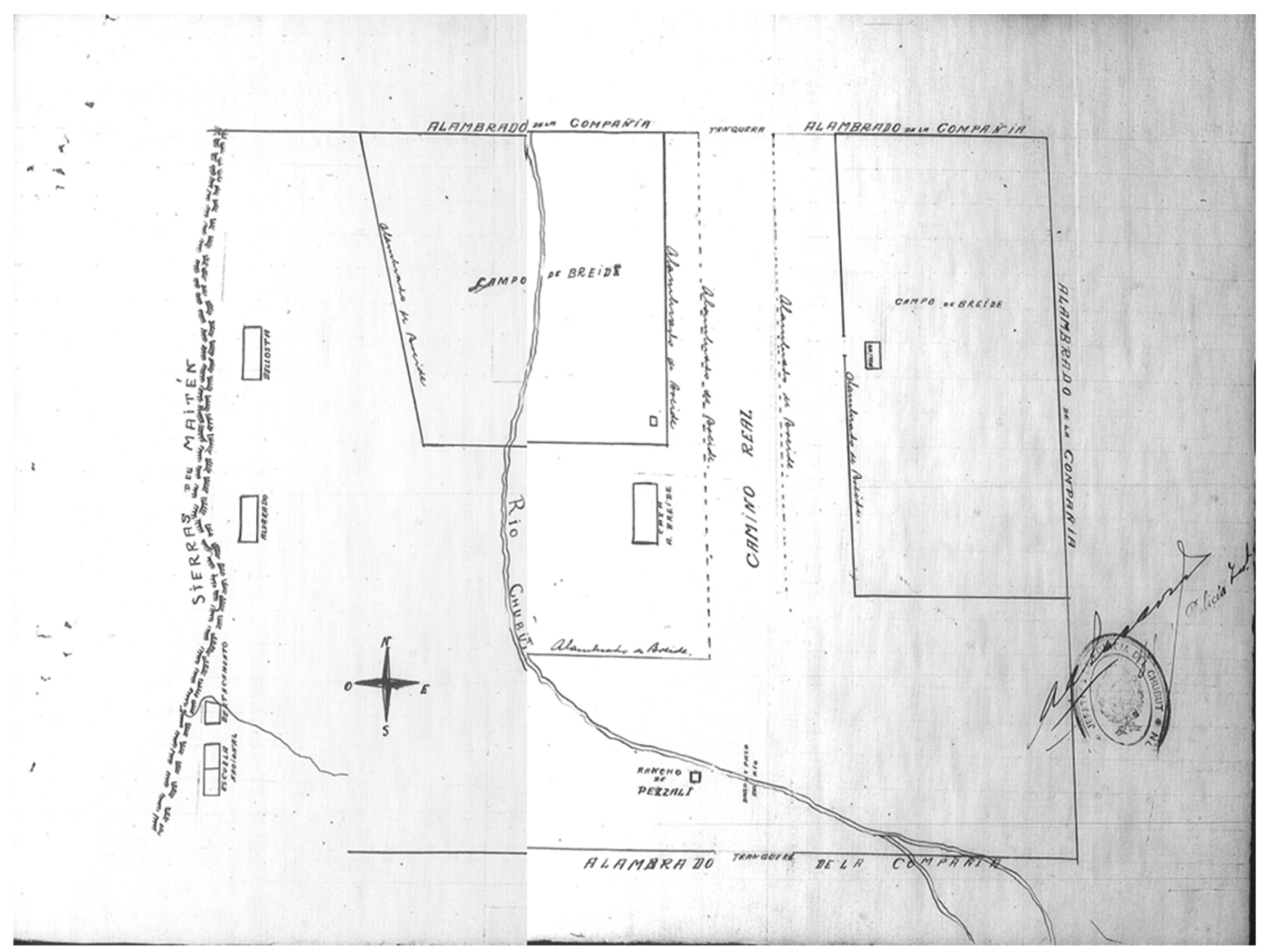

Fig. 4. Croquis del lote dos, fracción B, sección JIII elaborado por la policía del Chubut (Archivo Histórico de la Provincia de Chubut, Fondo Gobernación del Chubut, expediente № 3535, 13/12/1921, fs. 80-81).

Para completar el expediente los funcionarios policiales realizaron una inspección ocular sobre el lote en cuestión, elaborando un croquis que detalló las principales características del terreno (Figura 4). En el plano se representaba el territorio en disputa, enmarcado en sus lados norte, este y sur por los alambrados de la ASLCo., y hacia el oeste por las sierras de El Maitén. El croquis reflejaba la centralidad del río Chubut y la encrucijada de caminos en el conflicto. Las otras ocupaciones que se registraron fueron las de Bellosta y Alvarado junto a las reparticiones estatales, representados con pequeñas cuadrículas sobre la línea de maitenes.

La policía registró que Breide ocupaba dos campos parcialmente alambrados, uno de los cuales se extendía sobre ambas márgenes del río, mientras que el segundo lo hacía sobre el lado oriental del valle de El Maitén. Se destacaban la casa de Breide y su molino harinero en la margen oriental ${ }^{21}$. En contraste, la ocupación de Pezzali que se encontraba en la margen sudoeste del río, frente a la balsa de pasajeros- era clasificada peyorativamente como "rancho".

21 El molino harinero de Breide fue uno de los primeros del noroeste del Chubut, estos emprendimientos particulares abastecieron a los pobladores de la región hasta la penetración de la empresa Molinos Río de la Plata, la cual ofrecería productos más económicos (María Marta Novella y Marcelo Troiano. "De Siembras y Molinos en el Noroeste del Chubut...". Realidad y Palabra. Boletín de la Unidad de Docencia e Investigación en Historia Americana y Argentina, UNPSJB, Vol. 2, № 2, Trelew, 1995, p. 18). 
El plano invisibilizaba a otros pobladores que se verían afectadas por el conflicto, representado sólo a aquellos que habían intervenido directamente en la causa. Esa decisión generaba la proyección de campos prácticamente vacíos, pasibles de ser fácilmente administrados por el estado. Asimismo, la presencia de los diferentes rectángulos y la intermitencia de los alambrados generaba una falsa idea de orden y de límites estables.

El 17 de julio se comisionó al subcomisario Horacio Izzo para que tomase una declaración ampliatoria a Pezzali, quien fundamentó sus avales en un acta firmada en 1920 por autoridades y vecinos del pueblo. Según ese documento Pezzali, en sociedad con Benito Crespo, lideraría la construcción del destacamento de policía y oficina de $\operatorname{correos}^{22}$. Suscribieron el acta el director de la escuela y presidente de la brigada de la liga patriótica local, Julio Chaparro, los agentes de policía Antonio Speroni y Segundo Miripil e Ismael Alvarado ${ }^{23}$. Según las memorias locales, el director de la escuela había tenido un rol protagónico en el reparto de tierras de la época, habiendo gestionado la distribución de parcelas en las proximidades del establecimiento escolar: "Quedaba a cargo del Director la autorización y la ubicación del lugar donde podría iniciar la construcción de la vivienda"24. Esa autoridad que se arrogaba Chaparro no era legal pero al parecer contaba con legitimidad local.

Pezzali sostuvo que los vecinos no se habían opuesto a la obra hasta que Breide regresó de un viaje comercial y los obligó a protestar. El ejemplo más elocuente era el de Alvarado, quien primero suscribió el acta y luego acompañó las denuncias del comerciante árabe. Afirmó que no tenía animales, agregando que la hectárea que ocupaba era puro pedregullo sin utilidad ganadera, lo que refutaba las acusaciones de sus vecinos linderos. Sostuvo finalmente que Breide, Bellosta y Alvarado se habían complotado contra él, sentenciando que: “...sólo ellos quieren vivir acaparando las tierras fiscales" 25 .

El comisario Izzo elevó las actuaciones, señalando que el conflicto era producto de la indeterminación de las ocupaciones, basadas en boletos de pastaje que reconocían los derechos a pastar hasta las tierras de los colindantes, generando una indefinición territorial sucesiva. En sus términos, las deficiencias de la ley de tierras generaban que: “...tres pobladores por añadidura extranjeros, se creen con títulos suficientes, a ser los únicos dueños de todo el Valle del Maitén, y que protestan tan pronto otro hombre quiere habitarlo, aún cuando fuera sin

\footnotetext{
${ }^{22}$ El acta figura adjunta a la denuncia de Benito Crespo contra Pedro Grimi por la destrucción de edificaciones sin previa notificación (Archivo Histórico de la Provincia de Chubut, Fondo Gobernación del Chubut, expediente № 3445, 05/10/1922).

${ }^{23}$ Antonio Speroni declaró en octubre de 1922 que el oficial Milton Roberts (anterior encargado de la comisaría Leleque) había autorizado el funcionamiento del destacamento en la casa de Breyer (Breide) pero que él "...resolvió sacarlo de esta casa, en virtud de que los gendarmes al servicio de este destacamento se embriagaban constantemente, cometiendo faltas e irregularidades de todas clases" (Archivo Histórico de la Provincia de Chubut, Fondo Gobernación del Chubut, expediente № 3445, 05/10/1922, f. 37).

${ }^{24}$ El Maitén, su historia..., Op. Cit., p. 44.

${ }^{25}$ Archivo Histórico de la Provincia de Chubut, Fondo Gobernación del Chubut, expediente № 3535, 13/12/1921, f. 77.
} 


\section{De bolichero turco a ganadero árabe. La construcción territorial de un inmigrante libanés en el noroeste del Chubut (1907-1927)}

hacienda"26. El comisario llegó a la conclusión de que el verdadero problema era que Breide temía que como Pezzali era cocinero de la $A S L C o$., se estableciese con una fonda que compitiera comercialmente con su boliche.

En agosto de 1922 la gobernación del Chubut ordenó el desalojo de Pezzali. En otro expediente ${ }^{27}$ se registró el telegrama que en noviembre Margarita Muñoz (mujer de Pezzali) envió a la gobernación solicitando una prórroga para el desalojo, que obtuvo una respuesta negativa. Cuando todo parecía concluido, el 22 de noviembre de 1922 la gobernación envió un telegrama a la policía de El Maitén exigiendo se detuviesen todas las actuaciones contra Pezzali y ordenando que no fuese molestado hasta la resolución definitiva de la Dirección de Tierras. No es posible saber si el viraje obedeció a una reconsideración del pedido de la familia o a la intercesión de la Oficina de Tierras, pero en cualquier caso significó un compás de espera en la causa.

En abril de 1923 Fortunato Aidar ${ }^{28}$, en calidad de apoderado de Breide, presentó una nueva denuncia contra Pezzali, alegando que este se había establecido con negocio de vino y caña. Para ello retomaba los argumentos sobre el perjuicio comercial, el supuesto extravío de animales, la violación del decreto del 4 de junio de 1917 y los derechos como primer poblador de su defendido. La gobernación constató que no existía permiso otorgado a Pezzali para el despacho de bebida ${ }^{29}$, ordenando la clausura del negocio y el nuevo cese de las construcciones ${ }^{30}$.

En mayo de 1923 Pezzali dirigió una carta al gobernador Franzoni reclamando ante lo que consideraba una tentativa injusta de desalojo. Su presentación fue acompañada por un aval de Martin Fennen ${ }^{31}$. Este último residía en la colonia 16 de Octubre, a unos 150 kilómetros del lugar del conflicto, lo que

\footnotetext{
${ }^{26}$ Archivo Histórico de la Provincia de Chubut, Fondo Gobernación del Chubut, expediente № 3535, 13/12/1921, f. 83.

${ }^{27}$ Archivo Histórico de la Provincia de Chubut, Fondo Gobernación del Chubut, expediente № 3899, $10 / 11 / 1922$.

${ }^{28}$ Fortunato Aidar pertenecía a la elite local del Valle inferior del río Chubut, era un comerciante, martillero y contador, además fue primer concejal de Trelew en dos períodos consecutivos entre 1920 y 1922 (Carlos Hernández. Capital comercial y elite local. Trelew y su hinterland: 1889-1930. Tesis de licenciatura Universidad Nacional de la Patagonia "San Juan Bosco", Trelew, 1999, pp. 73 y 122).

${ }^{29}$ Según la nómina de comercios habilitados para el expendio de bebidas en la provincia del Chubut correspondiente al período 1924-1926, el único boliche habilitado en el paraje El Maitén era el de Breide (Archivo Histórico de la Provincia de Chubut, Fondo Gobernación del Chubut, expediente № 3346, 02/06/1926).

${ }^{30}$ A finales de ese mismo año Pezzali presentaría una solicitud de despacho de bebidas ante la gobernación (Archivo Histórico de la Provincia de Chubut, Fondo Gobernación del Chubut, expediente № 5512, 26/12/1923).

${ }^{31}$ Fennen era un prestigioso comerciante de la Colonia 16 de Octubre que tenía además negocios en Trelew. Se había consolidado en el valle inferior del río Chubut con la firma Carrasco y Fennen, orientándose a la ganadería a partir de 1919 con una importante estancia en las cercanías de Esquel, llegando a ocupar el cargo de Presidente de la Sociedad Anónima Ganadera e Industrial del Chubut (El pueblo, Año II, $\mathrm{N}^{\circ}$ 106, 01/01/1919, p. 21). Asimismo, Fennen fue presidente del consejo municipal de Trelew entre 1917 y 1918 y concejal por el mismo pueblo entre 1918 y 1920 (Carlos Hernández. Capital comercial..., Op. Cit., p. 122).
} 


\section{Matías Rodrigo Chávez}

refleja la amplitud territorial de los contactos puestos en juego. Fennen informaba que tenía: “...entendido que este asunto es puramente de intereses del turco Abraham Breide, que quiere impedir con su dinero, el trabajo de un pobre, que tiene como único capital su honestidad y voluntad de trabajar"32. El ataque a Breide era directo y el calificativo de turco reforzaba la carga negativa, mientras que el acento estaba puesto en las desigualdades económicas que al parecer podían torcer la decisión final en favor del comerciante árabe.

Tanto los apoderados legales como los prestigiosos vecinos que avalaban a las partes, son un indicio de las complejas redes de influencias que se tejían. Fisch había señalado este tipo de prácticas como característico de la administración de tierras durante esos años: "... sujeta a la parsimonia, reglamentaciones, complicaciones, expedientes, cuando no (como hace pocos años) a las recomendaciones, influencias y arbitrariedades de oficinas públicas, para tener una idea más o menos acabada del paño"33. En buena medida la puja territorial quedaba supeditada a la capacidad de las partes de movilizar sus influencias, en un contexto signado por la confusión administrativa y por las concesiones superpuestas que dificultaban la operatividad del sistema ${ }^{34}$.

El octubre de 1923 Breide realizó una nueva denuncia ante el gobernador interino Julio Berdera, aduciendo que Pezzali había introducido nuevas mejoras y que continuaba vendiendo bebidas alcohólicas, manifestando que los peones de la ASLCo. se embriagaban diariamente en el boliche de Pezzali y producían escándalo ${ }^{35}$. En su declaración del 18 de enero de 1924 ante el comisario Milton Roberts, Pezzali reconoció que había reiniciado actividades comerciales con su fonda, ocupándose del despacho de vinos, cerveza y tabaco.

Quedaba claro al final del litigio que el enfrentamiento profundo obedecía a competencia de las territorialidades bolicheras de Breide y Pezzali. En última instancia, no era una pugna por el valor productivo de la tierra sino por las redes comerciales que se podían tender a partir de ese punto estratégico. El 16 de abril de 1925 Pezzali realizó un último intento por obtener avales para alambrar ${ }^{36}$, alegando permiso verbal del Jefe de Tierras Adolfo Raffo, pero la respuesta de las autoridades fue negativa. Por un expediente subsiguiente, a propósito del cobro de sueldos de agentes de policía, sabemos Pezzali se radicó en el pueblo General Roca (Río Negro) a mediados de $1925^{37}$.

\footnotetext{
32 Archivo Histórico de la Provincia de Chubut, Fondo Gobernación del Chubut, expediente № 3535, 13/12/1921, f. 131.

${ }^{33}$ Ricardo Fisch. Cuestiones patagónicas..., Op. Cit., p. 25.

${ }^{34}$ Noemí Girbal-Blacha. "Política de tierras públicas en la Argentina (1916-1930). El caso de los territorios nacionales del Sur". Revista de Historia del Derecho, № 19. Buenos Aires, 1991, p. 233.

${ }^{35}$ Los pobladores Aristes Fernández, Santiago Gómez Aguilar y Segundo Guajardo testificaron corroborando el comercio ilegal de Pezzali.

${ }^{36}$ Archivo Histórico de la Provincia de Chubut, Fondo Gobernación del Chubut, expediente № 0404P, 16/04/1925.

${ }^{37}$ Archivo Histórico de la Provincia de Chubut, Fondo Gobernación del Chubut, expediente № 0405P, 16/04/1925.
} 


\section{De bolichero turco a ganadero árabe. La construcción territorial de un inmigrante libanés en el noroeste del Chubut (1907-1927)}

Este largo enfrentamiento refleja la falta de comunicación y la superposición de organismos estatales ${ }^{38}$, mostrando que los actores aprendieron a moverse aprovechando las contradicciones y los solapamiento de las agencias estatales, acelerando o dilatando el conflicto según la coyuntura. Sin dudas la disputa estuvo signada por el desgaste de las partes, considerando que todas las denuncias implicaban el costo de los telegramas, el traslado hasta los distintos destacamentos, el pago a los apoderados y la cobertura de la reposición de sellados al finalizar el trámite administrativo.

El conflicto se resolvió en favor de Breide, quien concretó la donación del edificio para la oficina de Correos como símbolo de la continuidad de su control sobre la territorialidad comercial de la región ${ }^{39}$. Dos años después el bolichero libanés accedería al arrendamiento del lote disputado, y de otros linderos, precipitando la crisis definitiva de las alianzas coyunturales entre vecinos criadores que se consideraban pioneros.

\section{La diversificación económica de Breide y el fin de una alianza}

En 1926 Abraham Breide obtuvo la autorización de la Dirección Nacional de Tierras y Colonias para arrendar parte de los lotes 2, 3, 8 y 9 de la fracción B, lo que implicaría una clara diversificación de sus negocios hacia la ganadería. Inmediatamente Breide solicitó el desalojo de las haciendas de sus vecinos: Ismael Alvarado, Segundo Guajardo, Segundo Miripil, Francisco Lempe, Bautista Cañiu, Paulino Calderero e Ildefonso Bellosta ${ }^{40}$. Es decir, Breide afectó a un gran número de vecinos linderos, incluyendo a quienes habían acompañado sus denuncias contra Pezzali y a quienes habían testificado en su favor. Según los informes policiales, la mayoría de los afectados aceptaron el desalojo, excepto Calderero y la sociedad de Bellosta/Uztarroz (titular de la sucesión Domínguez), quienes resistieron el desalojo hasta 1927.

\footnotetext{
${ }^{38}$ Susana Bandieri y Graciela Blanco. "Política de tierras en los Territorios Nacionales: entre la norma y la práctica", en Graciela Blanco y Guillermo Banzato (compiladores), La cuestión de la tierra pública en Argentina. A 90 años de la obra de Miguel Ángel Cárcano. Rosario, Prohistoria ediciones, 2009, p. 167.

${ }^{39}$ La Oficina de correos aceptó la donación de Breide (Archivo Histórico de la Provincia de Chubut, Fondo Gobernación del Chubut, expediente № 3312, 26/09/1922). Se instaló una placa conmemorativa recordando la donación en el edificio en el que funcionó la repartición entre 1923 y 1948. Según una breve semblanza sobre Breide del Diario Esquel, este también habría donado el edificio del Juzgado de Paz, además de colaborar en la edificación de la comisaría y de contribuir en la construcción de dos escuelas (Diario Esquel. Número Especial del Diario Esquel en sus Bodas de Plata, Esquel, 1950, Esquel, 25/02/1950, p. 128).

${ }^{40}$ Cabría agregar a estos vecinos criadores al bolichero Francisco Wodicka, quien también denunció el levantamiento de alambrados de Breide "con cooperación de la policía", los cuales aislaban su comercio (Archivo Histórico de la Provincia de Chubut, Fondo Gobernación del Chubut, expediente № 3351, 02/06/1926).
} 
En junio de 1926 Bellosta presentó un reclamo contra Breide ante la Oficina de Tierras, denunciando la construcción de alambrados sin mensuras aprobadas ${ }^{41} \mathrm{y}$ la introducción de hacienda en sus poblaciones. Dicha repartición inició entonces un expediente ${ }^{42}$ ante la gobernación del Chubut, ordenando a Breide que se abstuviese de realizar mejoras hasta tanto se resolviese el pleito. El 29 de junio Bellosta amplió su denuncia, alegando que el comerciante árabe había introducido mejoras, corrales y majadas. En ese expediente se sumó la denuncia de Paulino Calderero (hijo), quien reclamaba que no habían recibido notificaciones previas de desalojo.

En la misma fecha Breide envió una carta a la comisaría de Norquinco, mediante Pascual Cañiu, contra-denunciando a Bellosta y Calderero. A los pocos días ratificó y amplió su denuncia en la misma comisaría, reclamando que le habían mezclado la hacienda, solicitando vigilancia policial y exigiendo garantías para él y sus intereses. El comisario ordenó el aparte de animales de Bellosta y Calderero en presencia de dos testigos.

En julio de 1926 el Jefe de Policía del Chubut comunicó a la comisaría de Ñorquinco que por orden de la gobernación se le permitía a Breide construir alambrados e introducir hacienda en los lotes en disputa. En septiembre se inició el nuevo proceso de desalojo ${ }^{43}$, Bellosta se opuso aduciendo que su socia había viajado a la Capital Federal para hacer valer sus derechos de primera pobladora y gestionar la anulación del arrendamiento a Breide.

La situación se mantuvo sin modificaciones hasta el 28 de abril de 1927, cuando el subinspector general de tierras comunicó a la gobernación que se había notificado a Bellosta y sucesión Domínguez que debían desalojar su hacienda de tierras otorgadas en arrendamiento a Breide ${ }^{44}$. En mayo Beovides, subcomisario de El Maitén, comunicó que Bellosta solicitaba aplazar tres meses el desalojo hasta que pudiese buscar un nuevo campo para sus 5.700 ovejas. Pedía que se considerara que sus animales no podían pastar en otro lugar considerando que en los campos linderos pastaban 15.500 ovejas de varios vecinos, a lo que se sumaba la imposibilidad de pastar en las sierras o campos de veranada durante esa época de año. Finalmente, el 11 de mayo de 1927 el subcomisario procedió al desalojo de 2.010 lanares de Bellosta, habilitando el cercamiento definitivo de Breide.

Este caso muestra claramente como un comerciante árabe, en su proceso de acumulación, decide confrontar con quienes habían funcionado como su propia base social. En determinado punto la diversificación de sus negocios implicó la decisión de atentar contra la red de alianzas que le habían resultado operativas en sus

\footnotetext{
${ }^{41}$ Recordemos que para la construcción de alambrados se requería de un permiso especial de la gobernación, el cual sólo se podía obtener previa mensura y aprobación de planos por parte de la Dirección Nacional de Tierras y Colonias.

${ }^{42}$ Archivo Histórico de la Provincia de Chubut, Fondo Gobernación del Chubut, expediente № 3351, 02/06/1926.

${ }^{43}$ Archivo Histórico de la Provincia de Chubut, Fondo Gobernación del Chubut, expediente № 5521, 21/10/1926.

${ }^{44}$ Archivo Histórico de la Provincia de Chubut, Fondo Gobernación del Chubut, expediente № 2159, 30/04/1927.
} 


\section{De bolichero turco a ganadero árabe. La construcción territorial de un inmigrante libanés en el noroeste del Chubut (1907-1927)}

enfrentamiento previos contra los competidores que habían desafiado su territorialidad.

Si bien pasarían algunas décadas hasta que los herederos de Breide obtuviesen los títulos de propiedad definitivos de esos y otros campos, las disputas territoriales de la década de 1920 marcaron una bisagra en el control territorial iniciado por Abraham. Valga como indicio que en las últimas alusiones en el marco de los procesos de desalojo, los agentes estatales se refieren a la tierra como propiedad de Breide, quien progresivamente dejaba de ser clasificado ambivalentemente como bolichero turco ${ }^{45}$ para comenzar a ser valorado positivamente como ganadero árabe.

\section{Conclusiones}

El micro-espacio cordillerano de El Maitén sirvió de escenario para analizar la trayectoria de ascenso del bolichero Abraham Breide a la luz de sus conflictos territoriales. Sus estrategias de acumulación estuvieron fuertemente atadas a la geografía de la región. La tierra fue su principal plataforma de acumulación, primero como punto desde el cual desplegó redes comerciales para controlar una territorialidad comercial extensa, la cual tuvo que disputar desde el momento que un nuevo poblador intentó superponer sus redes de negocios.

El largo conflicto con Pezzali representó la puja de Breide por mantener y consolidar su territorialidad bolichera. Imponerse fue demostrar que podía movilizar a los pobladores linderos en su favor y soportar la presión de otros vecinos notables con capacidad de influir sobre los agentes estatales. En tal sentido, el principal símbolo del litigio fue la carrera por concretar la donación del destacamento de policía y la oficina de correos. En ese contexto, efectivizar la donación de edificios públicos representaba la posibilidad de sellar una relación de reciprocidad con las agencias estatales y beneficiarse de sus concesiones.

Como vimos, la prolongación del conflicto se explicaba por las distancias y la superposición de instancias estatales, pero también por la alta movilidad de los funcionarios y los cambios de administraciones. En última instancia, la resolución del conflicto dependió de una inestable red de influencias y presiones sobre los agentes de estado. En ese sentido es posible que Breide estuviese en mejores condiciones socio-políticas y económicas que su rival para soportar un largo litigio de desgaste.

A partir del permiso de arrendamiento a Breide -y la ejecución de las órdenes de desalojo a su vecinos linderos-, se abrió una nueva etapa caracterizada por su devenir ganadero y por su ruptura de la alianza que lo había sostenido en sus enfrentamientos previos. La territorialidad de Breide entraba así en una nueva

\footnotetext{
45 Para profundizar sobre el lugar ambivalente de los bolicheros árabes en la Patagonia Central véase Matías Chávez y Marcos Sourrouille. "Redes sociales y territorialidad bolichera de sirios y libaneses en el sudeste de Río Negro, Argentina (1900-1950)". Anuario de Historia Regional y de las Fronteras, Vol. 21, N 1 . Bucaramanga, 2016, pp. 159-181.
} 


\section{Matías Rodrigo Chávez}

etapa, período que estaría signado por los cercamientos y por la continuidad de su proceso de acumulación.

\section{Fuentes}

Archivo Histórico de la Provincia de Chubut, Fondo Gobernación del Chubut. Instituto Autárquico de Colonización y Fomento Rural, Inspecciones Generales de Tierras, sección JIII, Chubut, 1920.

Diario Esquel. Número Especial del Diario Esquel en sus Bodas de Plata, Esquel, 25/02/1950.

Diario El Pueblo, Trelew, Año II, N 106, 01/01/1919.

\section{Bibliografía}

Brígida Baeza. Fronteras e identidades en Patagonia central (1885-2007). Rosario, Prohistoria ediciones, 2009.

Susana Bandieri y Graciela Blanco. "Política de tierras en los Territorios Nacionales: entre la norma y la práctica", en Graciela Blanco y Guillermo Banzato (compiladores), La cuestión de la tierra pública en Argentina. A 90 años de la obra de Miguel Ángel Cárcano. Rosario, Prohistoria ediciones, 2009.

Alejandro Benedetti. "Territorio: concepto integrador de la geografía contemporánea", en Patricia Souto, (coordinadora), Territorio, lugar, paisaje. Prácticas y conceptos básicos en geografía. Buenos Aires, Editorial de la Facultad de Filosofía y Letras de la Universidad de Buenos Aires, 2011.

Graciela Blanco. "Los ocupantes de tierras en la Norpatagonia. Los Inspectores nacionales, el colono ideal y el poblador real al comenzar el siglo XX". Historia Regional, Vol. XXIX. Villa Constitución, 2016, pp. 51-66.

Matías Chávez y Marcos Sourrouille. "Redes sociales y territorialidad bolichera de sirios y libaneses en el sudeste de Río Negro, Argentina (1900-1950)". Anuario de Historia Regional y de las Fronteras, Vol. 21, № 1 . Bucaramanga, 2016, pp. 159-181. Liliana Figueroa. "Las tierras destinadas a pastos comunes en Cholila: aportes para definir al sujeto poblador y pensar los cambios en el uso y tenencia de la tierra". Revista Hermeutic, № 9. Río Gallegos, 2010, pp. 1-22.

Débora Finkelstein y María Marta Novella. Poblamiento del Noroeste del Chubut. Aportes para su historia. Esquel, Fundación Ameghino, 2005.

Débora Finkelstein. "Mecanismos de acceso a la tierra y narraciones de identidad en la colonia pastoril aborigen de Cushamen (provincia del Chubut)". Cuadernos del Instituto Nacional de Antropología y Pensamiento Latinoamericano, № 19. Buenos Aires, 2001, pp. 231-247.

Débora Finkelstein, María Marta Novella y Marcelo Gavirati. "Ocupación de la tierra pública en el noroeste del Chubut. Poblamiento y producción agropecuaria en el valle de Cholila, sección JIII, (1900-1919)". II Congreso de Historia Social y Política de la Patagonia argentino-chilena, Trevelin, 1997.

Ricardo Fisch. Cuestiones patagónicas. Tierras fiscales y otros problemas. Buenos Aires, Kidd, 1932. 


\section{De bolichero turco a ganadero árabe. La construcción territorial de un inmigrante libanés en el noroeste del Chubut (1907-1927)}

Noemí Girbal-Blacha. “Política de tierras públicas en la Argentina (1916-1930). El caso de los territorios nacionales del Sur". Revista de historia del derecho, № 19. Buenos Aires, 1991, pp. 209-243.

Carlos Hernández. Capital comercial y elite local. Trelew y su hinterland: 1889-1930. Tesis de licenciatura Universidad Nacional de la Patagonia "San Juan Bosco", Trelew, 1999.

Gabriela Macchi. "Los sirio-libaneses y su participación en el temprano desarrollo económico del noroeste del Chubut 1900-1940". X Congreso de Historia Social y Política de la Patagonia Argentino-Chilena, Trevelin, 2013.

Ernesto Maggiori. 6 historias patagónicas. Trelew, Remitente Patagonia, 2017.

El Maitén, su historia...su poblamiento.... El Maitén, Municipalidad del Maitén, 2006.

Marcelino Martínez. La Patagonia Central. Descripción física y política de la Gobernación del Chubut. Buenos Aires, Lajuane y Cía. Editores, 1913.

Eduardo Míguez. Las Tierras de los ingleses en la Argentina 1870-1914. Buenos Aires, Editorial de Belgrano, 1985.

Ramón Minieri. Ese ajeno sur. Viedma, Fondo Editorial Rionegrino, 2006.

María Marta Novella y Marcelo Troiano. "De Siembras y Molinos en el Noroeste del Chubut...". Realidad y Palabra. Boletín de la Unidad de Docencia e Investigación en Historia Americana y Argentina, UNPSJB, Vol. 2, № 2, Trelew, 1995, pp. 16-36.

Juan Manuel Palacio. La paz del trigo. Cultura legal y sociedad local en el desarrollo agropecuario pampeano, 1890-1945. Buenos Aires, Edhasa, 2004.

Juan Pro Ruiz. "Introducción. Mensuras, catastro y construcción estatal", en Juan Carlos Garavaglia y Pierre Gautreau, (editores), Mensurar la tierra, controlar el territorio. América Latina, siglos XVIII-XIX. Rosario, Prohistoria ediciones, 2011.

Alejandro Schamún. La colectividad siria en la República Argentina. Buenos Aires, s/d, 1910.

Marcos Sourrouille. Nahuelpan, Colonia 16 de octubre y Argentine Southern Land Co.: la colonización del territorio nacional del Chubut (1885-1937). Tesis doctoral Universidad de Buenos Aires, Buenos Aires, 2017.

Recibido: $13 / 06 / 2018$

Evaluado: $22 / 07 / 2018$

Versión Final: 01/08/2018 